\title{
REMOÇÃO DE ÓLEO DE ÁGUAS PRODUZIDAS DA INDÚSTRIA DE PETRÓLEO UTILIZANDO ARGILA NACIONAL BENTONITA ORGANOFÍLICA
}

\author{
J. N. PEREIRA ${ }^{1}$, A. M. D, OLIVEIRA ${ }^{1}$, K. S. M. G. SOUZA ${ }^{1}$, G. Z. CLERICUZI $^{1}$ \\ ${ }^{1}$ Universidade Federal da Paraíba, Departamento de Engenharia Química \\ E-mail para contato: juli.nascimento.17@hotmail.com, ana.mariadantas10@gmail.com, \\ clericuzi.zc@gmail.com
}

\begin{abstract}
RESUMO - Na indústria do petróleo há sempre geração de resíduos prejudiciais ao meio ambiente. Devido a esse fato há necessidade de aprimoramento de técnicas para descartar estes resíduos dentro dos limites estabelecidos pela legislação vigente. Assim, técnicas alternativas vêm sendo desenvolvidas com o objetivo de se empregar trocadores iônicos naturais, como as argilas, que apresentem uma boa disponibilidade para um processo de remoção eficiente. Nesse trabalho foi realizada a análise do desempenho da argila nacional bentonita organofílica como adsorvente na remoção de óleo. Inicialmente foi realizada a organofilização da argila, ou seja, o tratamento com o sal quaternário de amônio, posteriormente a argila foi caracterizada, para comprovar a eficiência do tratamento. Os experimentos são realizados pelo processo de adsorção em banho finito utilizando a água produzida adquirida na indústria do petróleo. Através dos resultados experimentais obtidos no processo de adsorção observou-se que a argila nacional bentonita organofílica apresentou-se bastante eficiente na remoção de óleo da água produzida.
\end{abstract}

\section{INTRODUÇÃO}

As águas residuais geradas em todas as etapas de processos da indústria do petróleo apresentam alto teor de óleo, sendo bastante prejudiciais ao meio ambiente. Devido a esse fato há necessidade de aprimoramento de técnicas para descartar estes resíduos dentro dos limites estabelecidos pela legislação vigente. No Brasil as resoluções no 357/2005 e 393/2007 do Conselho Nacional do Meio Ambiente (CONAMA) determinam a concentração máxima de óleo que um efluente industrial pode ter para que o descarte seja realizado. Sendo necessário algum tratamento prévio, assim técnicas alternativas vêm sendo desenvolvidas com o objetivo de se empregar trocadores iônicos naturais, como as argilas na remoção de óleo. As argilas exibem alta seletividade e uma alta capacidade de troca, por esta razão, estão sendo estudadas para este processo de remoção. Além disso, possuem baixo custo e são abundantes na natureza. Quando em sua forma natural, a remoção de compostos orgânicos é limitada. A modificação superficial de argilas permite ampliar os horizontes de aplicação das argilas, gerando novos materiais e novas aplicações. A inserção de moléculas orgânicas (organofilização) faz com que ocorra expansão entre os planos da argila, e muda sua natureza hidrofílica para organofílica e com isso proporciona a possibilidade de aplicações na remoção eficiente de compostos orgânicos (Paiva et al., 2008). Podendo ser utilizadas, de forma eficiente, para realizar o tratamento da água produzida. Nesse trabalho foi realizada uma 
avaliação do desempenho da argila nacional bentonita Verde Claro organofílica como adsorvente na remoção de óleo de águas produzidas da indústria do petróleo.

\section{METODOLOGIA}

\subsection{Preparação da argila organofílica}

Foi utilizado o mesmo método de preparação de Pereira et al. (2007). A preparação da argila foi realizada conforme o procedimento descrito no fluxograma, como mostra a figura 1. Foi utilizada a argila nacional bentonita Verde Claro e o sal quaternário de amônio Cloreto de estearildimetil amônio (Praepagen).

Figura 1 - Fluxograma da preparação da argila organofílica.

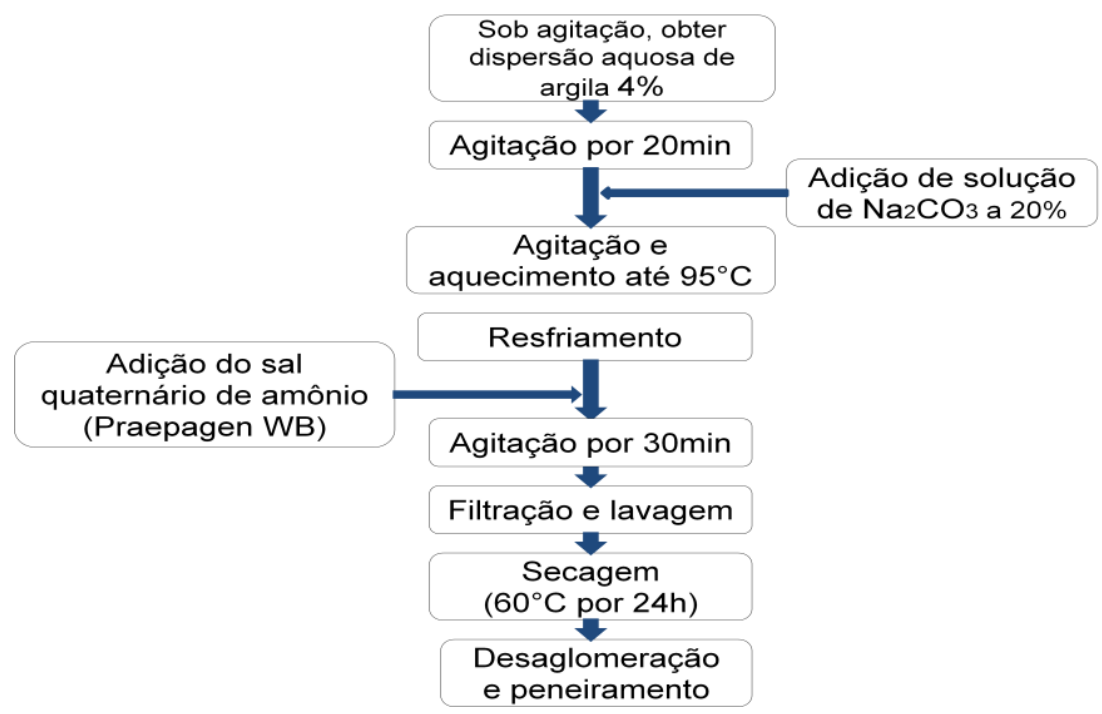

\subsection{Caracterização da argila}

Foi realizada a caracterização das argilas antes e após a organofilização através de técnicas e métodos analíticos, visando comprovar a eficiência do tratamento realizado, sendo estes, Difração de Raios X (DRX) e Espectroscopia de absorção na região do Infravermelho (FT-IR).

\subsection{Ensaios de banho finito}

Os experimentos foram realizados pelo processo de adsorção em banho finito utilizando a água produzida adquirida na indústria do petróleo.

Como se deseja avaliar a remoção do óleo presente na água produzida utilizando a argila organofílica como adsorvente, as condições para cada ensaio foram determinadas através do planejamento experimental.

Os ensaios foram preparados adicionando $1 \mathrm{~g}$ de argila organofílica a erlenmeyers contendo $50 \mathrm{~mL}$ da água produzida. Em seguida, levou-se os erlenmeyers para a agitação 
mecânica em um Shaker, com rotação de $240 \mathrm{rpm}$, durante 5 horas, sob as condições determinadas no planejamento experimental.

\subsection{Planejamento experimental}

Foi adotado um planejamento fatorial de $2^{2}$ com três repetições do ponto central, com a finalidade de avaliar a tendência para maximizar a eficiência do processo, foi utilizado o Delineamento Composto Central Rotacional (DCCR), adicionou-se 4 ensaios nas condições axias. As variáveis selecionadas foram o $\mathrm{pH}$, mantido na faixa entre 2 e 8 , e a temperatura, mantida dentro da faixa de 25 e $42^{\circ} \mathrm{C}$, conforme o planejamento experimental apresentado na Tabela 1.

Tabela 1 - Planejamento fatorial $2^{2} \operatorname{com} 3$ pontos centrais e 4 axiais.

\begin{tabular}{|c|c|c|}
\hline Ensaios & $\mathrm{pH}$ & Temperatura $\left({ }^{\circ} \mathrm{C}\right)$ \\
\hline 1 & 3 & 28 \\
\hline 2 & 7 & 28 \\
\hline 3 & 3 & 40 \\
\hline 4 & 7 & 40 \\
\hline 5 & 2 & 34 \\
\hline 6 & 8 & 34 \\
\hline 7 & 5 & 25 \\
\hline 8 & 5 & 42 \\
\hline 9 & 5 & 34 \\
\hline 10 & 5 & 34 \\
\hline 11 & 5 & 34 \\
\hline
\end{tabular}

\subsection{Determinação do Percentual de Óleo Removido e Capacidade de Adsorção}

Método do Clorofórmio: Para determinar a quantidade de óleo presente na água a técnica consistiu em coletar $5 \mathrm{~mL}$ da amostra a ser analisada e adicionou-se $5 \mathrm{~mL}$ de clorofórmio. Agitou-se por alguns minutos e após a separação da fase, foi feita a coleta da fase solvente (clorofórmio + óleo). Foi realizada a leitura da absorbância, no comprimento de 262nm no espectrofotômetro de UV-Visível (Cunha et al., 2014). E por meio da curva de calibração foi possível determinar a concentração de óleo na amostra.

Percentual de remoção e capacidade de adsorção no equilíbrio: $O$ percentual de remoção de óleo e a capacidade de remoção do óleo em equilíbrio ( $\mathrm{q}_{\mathrm{eq}}$ ) são determinadas através das Equações 1 e 2, respectivamente, abaixo:

$$
\begin{gathered}
\% \text { Rem }=\left(\frac{C_{0}-C_{f}}{C_{0}}\right) * 100 \\
\mathrm{q}_{\mathrm{eq}}=\frac{V}{m}\left(C_{0}-C_{e}\right)
\end{gathered}
$$

Onde: V: volume da solução $(\mathrm{mL}) ; \mathrm{m}$ : massa de adsorvente $(\mathrm{g}) ; \mathrm{C}_{0}$ : concentração inicial da solução $(\mathrm{mg} / \mathrm{L}) ; \mathrm{C}_{f}$ : concentração final da solução $(\mathrm{mg} / \mathrm{L})$ e $\mathrm{C}_{\mathrm{e}}$ : concentração no equilíbrio $(\mathrm{mg} / \mathrm{L})$. 


\section{RESULTADOS E DISCUSSÃO}

\subsection{Caracterização das argilas natural e organofílica}

Difração de Raios X (DRX): A figura 2 apresenta as curvas de difração de raios $\mathrm{X}$ das argilas natural (PMT-1) e organofílica (PMT-1 ORG).

Figura 2- Difratogramas da argila Verde Claro natural (PMT-1) e organofílica (PMT-1 ORG).

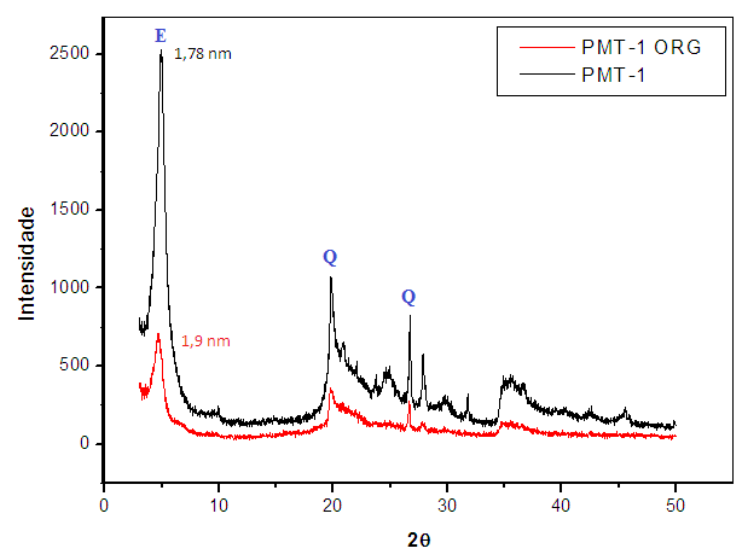

Observando os difratogramas é possível verificar picos característicos das bentonitas, que tem como argilomineral predominante esmectita (E), observa-se também picos referentes ao quartzo (Q), um mineral não esmectítico que se apresenta como impureza, essas características foram observadas também por Rodrigues (2009).

Comparando as curvas observa-se que ocorreu o deslocamento do pico esmectítico na argila organofílica, os valores observados foram de $1,78 \mathrm{~nm}$ para a argila natural e $1,9 \mathrm{~nm}$ para a argila organofílica, evidenciando o aumento do espaçamento basal em relação à argila natural, confirmando a intercalação do sal orgânico na estrutura da argila, ou seja, a organofilização.

Espectroscopia de absorção na região do Infravermelho (FT-IR): Os espectros (FT-IR) das argilas natural e organofílica estão apresentados nas figuras $3 \mathrm{a}$ e $3 \mathrm{~b}$, respectivamente.

Figura 3 - FT-IR da (a) argila natural (PMT-1) e (b) organofílica (PMT-1 ORG).
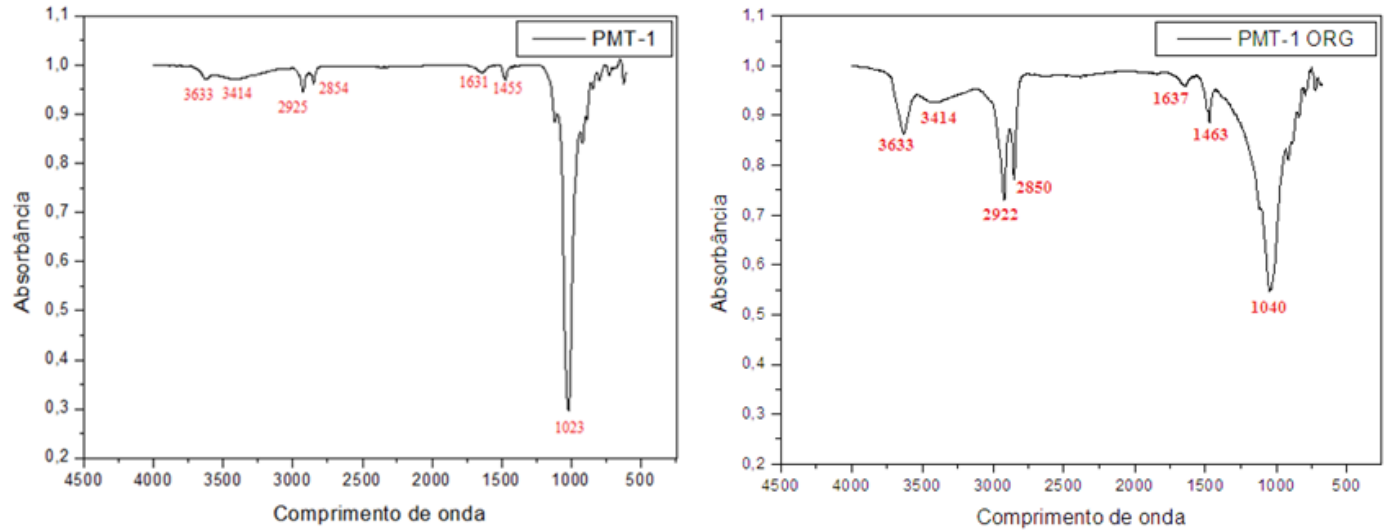
Observando os espectros na região do infravermelho (FT-IR) da argila natural (PMT1) e da argila organofílica (PMT-1 ORG), verifica-se que na argila organofílica há presença acentuada de bandas correspondentes a intercalação do sal quaternário de amônio. Observa-se uma banda na faixa de $2922 \mathrm{~cm}^{-1}$ correspondente as vibrações de estiramento assimétrico do grupo $\mathrm{CH}_{2}$, outra na faixa de $2850 \mathrm{~cm}^{-1}$ correspondente as vibrações de estiramento simétrico do grupo $\mathrm{CH}_{2}$ e também uma banda na faixa de $1463 \mathrm{~cm}^{-1}$ corresponde às vibrações de flexão do grupo $\mathrm{CH}_{3}$. A presença de bandas de absorção referentes aos grupos $\mathrm{CH}_{2} \mathrm{e} \mathrm{CH}_{3}$ nos espectros infravermelhos da argila organofílica evidenciam que ocorreu a intercalação do cátion quaternário de amônio na argila.

\subsection{Avaliação da remoção de óleo da água produzida}

Os resultados obtidos para a porcentagem de remoção do óleo na água produzida utilizando a argila Verde Claro organofílica como adsorvente estão apresentados na Tabela 2.

Tabela 2 - Resultados obtidos para a remoção do óleo de água produzida.

\begin{tabular}{|c|c|c|c|}
\hline Ensaio & $\mathrm{C}_{0}(\mathrm{mg} / \mathrm{L})$ & $\mathrm{C}(\mathrm{mg} / \mathrm{L})$ & $\%$ Rem \\
\hline 1 & 118 & 4,03 & 96,59 \\
\hline 2 & 118 & 10,06 & 91,47 \\
\hline 3 & 118 & 10,06 & 91,47 \\
\hline 4 & 118 & 14,09 & 88,06 \\
\hline 5 & 118 & 6,04 & 94,88 \\
\hline 6 & 118 & 14,09 & 88,06 \\
\hline 7 & 118 & 6,04 & 94,88 \\
\hline 8 & 118 & 12,08 & 89,77 \\
\hline 9 & 118 & 12,08 & 89,77 \\
\hline 10 & 118 & 10,06 & 91,47 \\
\hline 11 & 118 & 12,08 & 89,77 \\
\hline
\end{tabular}

Através dos resultados experimentais obtidos verifica-se que foram obtidos bons percentuais de remoção, indicando que a argila organofílica apresentou uma boa eficiência na remoção de óleo na água produzida. E que o maior percentual de remoção (\%Rem) de óleo é obtido para o ensaio 1, cujas condições foram temperatura de $28^{\circ} \mathrm{C}$ e $\mathrm{pH} 3$.

Os resultados foram analisados por meio de uma análise de variância (ANOVA) para estimar os parâmetros estatísticos e avaliar o modelo matemático. Através dessa análise observou-se que as variáveis estudadas são estatisticamente significativas.

\section{CONCLUSÕES}

A partir dos difratogramas de Raio X foi possível comprovar que a amostra de argila Verde Claro natural utilizada trata-se de uma argila esmectítica e também que o método de organofilização utilizado é eficiente na obtenção da argila organofílica. Isso foi observado através do aumento do espaçamento basal de $1,78 \mathrm{~nm}$ na argila natural, para $1,90 \mathrm{~nm}$ na argila modificada com o sal quaternário de amônio. Esses resultados mostram que os sais foram 
incorporados à estrutura da argila, evidenciando assim o processo de organofilização. Através dos espectros de infravermelho pode-se observar o surgimento de picos acentuados nas bandas correspondentes a intercalação do sal quaternário de amônio nos espaços interlamelares da argila, bandas de absorção referentes aos grupos $\mathrm{CH}_{2} \mathrm{e} \mathrm{CH}_{3}$. Essa inserção de moléculas orgânicas faz com que ocorra expansão entre os planos da argila, mudando sua natureza de hidrofílica para organofílica, possibilitando uma maior eficiência na remoção de compostos orgânicos de baixa solubilidade na água, como óleos.

Através dos ensaios realizados observou-se que a argila organofílica apresenta uma boa eficiência na remoção de óleo em água produzida. Sendo o maior percentual de remoção de óleo é obtido para temperatura de $28^{\circ} \mathrm{C}$ e $\mathrm{pH} 3$.

Com base nos resultados obtidos para a remoção de óleo da água produzida, a utilização de argilas organofílicas no processo de separação óleo/água poderá oferecer uma nova opção de tratamento de efluentes oleosos antes do seu descarte.

\section{REFERÊNCIAS}

CUNHA, R. S. S.; MOTA, J. D.; RODRIGUES, M. G. F. Síntese, caracterização estrutural e aplicação de argila organofílica na remoção de óleo lubrificante e óleo diesel no processo de adsorção em sistema de banho finito. In $\mathrm{X}$ Encontro Brasileiro sobre Adsorção, Guarujá, SP, 2014.

MINISTÉRIO DO MEIO AMBIENTE. Conselho Nacional do Meio Ambiente - CONAMA. Resolução no 357, de 17 de março de 2005.

MINISTÉRIO DO MEIO AMBIENTE. Conselho Nacional do Meio Ambiente - CONAMA. Resolução no 393, de 8 de agosto de 2007.

PAIVA, L. B. DE; MORALES, A. R.; DÍAZ, F. R. V. Argilas organofílicas: características, metodologias de preparação, compostos de intercalação e técnicas de caracterização. Cerâmica, v. 54, 2008.

PEREIRA, K. R. O.; RODRIGUES， M. G. F.; VALENZUELA-DIAZ，F. R. Síntese e caracterização de argilas organofílicas: comparação no uso de dois métodos. Revista Eletrônica de Materiais e Processos. v. 2, p.1-8, 2007.

RODRIGUES, S. C. G. Preparação e caracterização de argilas organofílicas em escala de laboratório, visando seu uso em sistema de separação emulsão óleo/água. Dissertação de Mestrado, Universidade Federal de Campina Grande, PB, 2009. 